\title{
ENHANCED MASTER CYCLE - SIGNIFICANT IMPROVEMENT OF STEAM RANKINE CYCLE
}

\author{
S. Głuch ${ }^{*}$, M. Piwowarski**
}

\begin{abstract}
The present paper focuses on an enhancement of the Master Cycle. In the first part, the paper presents a classical Master Cycle which is a modification of the double reheat Rankine cycle. This modification allows to slightly increase efficiency, resolves problems caused by superheated steam on bleeds and decreases mass flow rate of steam directed to reheat. These improvements include the implementation of a tuning turbine from which a few bleeds are taken. In the proposed Enhanced Master Cycle all bleeds are placed on the tuning turbine. This alteration results in an increased efficiency, further reduction of steam mass flow on reheats and simplification of low pressure turbine. Comparative calculations of the double reheat cycle, Master Cycle and Enhanced Master Cycle are presented. Cycles operate on the advanced ultra-supercritical parameters. The Enhanced Master Cycle achieved the highest net efficiency $54.64 \%$ and required the lowest steam mass flow on superheaters.
\end{abstract}

\section{Keywords: Master Cycle, Rankine Cycle, Ultra-supercritical Steam Turbine, Double Reheat Cycle}

\section{Introduction}

Modern steam power plants do need to meet strict environmental restrictions and ruthless economics requirements. Flue gases cannot exceed limits of $\mathrm{NO}_{\mathrm{x}}, \mathrm{SO}_{2}$ and other pollutants. Increasing costs of fuel and $\mathrm{CO}_{2}$ certificates impose high efficiency of electricity generation. Furthermore, power grid needs reliable and stable source of electricity which cannot be significantly affected by weather conditions. All these requirements could be fulfilled by modern ultra-supercritical (USC) steam power plants. New generation of nuclear plants will be able to generate fresh steam on parameters high enough for USC cycles. Most significant revolution in Power Engineering in upcoming future could be an implementation of the nuclear fusion. Since fusion energy would have to be turned into electricity, USC steam cycle is currently the most efficient method of heat conversion into electricity. Steam Rankine cycle should remain significant power source in upcoming years. Currently, Advanced Ultra-supercritical (AUSC) power plants are being developed. The fresh steam parameters of this generation exceed $620^{\circ} \mathrm{C}$ and $30 \mathrm{MPa}$. European $\mathrm{AD} 700$ is the biggest program which aims to develop steam power plants operating at the fresh steam parameters exceeding $700^{\circ} \mathrm{C}$. (Tumanovskii et al., 2017 and Piwowarski, 2009) Researchers are working on the development and testing of new refractory materials. Construction of the first AUSC power unit is planned between 2020 - 2025. The biggest drawback of AUSC technology is that it needs to use very expensive nickel and cobalt based super alloys for components which are affected by extreme temperatures. This paper presents a solution which increases net efficiency and allows to reduce the amount of costly refractory materials.

\section{Master Cycle}

Master Cycle (MC) is a modification of the double reheat steam Rankine cycle. The double reheat cycle solves a problem of wetness at last blade rows, but increases difficulties and costs of bleeds and heat exchangers. Bleed of steam at supercritical parameters results in exergy losses. MC introduces additional turbine called tuning turbine (TT). A part of steam exhausting from high pressure is directed to it. Intermediate pressure turbine bleeds are moved to the tuning turbine. This solution have a few important benefits: cycle efficiency is increased due to exergy savings, steam mass flow on expensive reheats is reduced and problems with costly supercritical bleed are resolved. (Kjaer and Dirnhaus, 2010)

\footnotetext{
* Staniław Głuch M.Sc.: Gdańsk Faculty of Mechanical Engineering, University of Technology, Street. Narutowicza 11/12, 80-233 Gdańsk, PL stach.gluch@gmail.com

** Assoc. Prof Marian Piwowarski DSc PhD.: Faculty of Mechanical Engineering, Gdańsk University of Technology, Streetl. Narutowicza 11/12, 80-233 Gdańsk, PL
} 


\subsection{Enhanced Master Cycle}

Enhanced Master Cycle (EMC) is a modification of the classic Master Cycle. In this case, all bleeds are placed at the tuning turbine. Because of that, steam mass flow through expensive reheaters is reduced. This design should also simplify the construction of an intermediate pressure and low pressure turbine. The low pressure turbine could have slightly higher internal efficiency due to removal of bleeds which disrupt flow. Efficiency of this cycle is higher than classic double reheat cycle. Under the assumption of same internal efficiencies, classic Master Cycle has slightly higher heat rate, but EMC could have higher heat rate under the assumption that internal efficiency of the low pressure turbine is 1 percentage point higher in EMC than in MC. In this case, the construction of TT is more complicated than in the classic Master Cycle. High wetness in the TT could be a problem, but moisture levels do not exceed levels that could be met inside the nuclear power plants. The scheme of EMC is presented in figure 1.

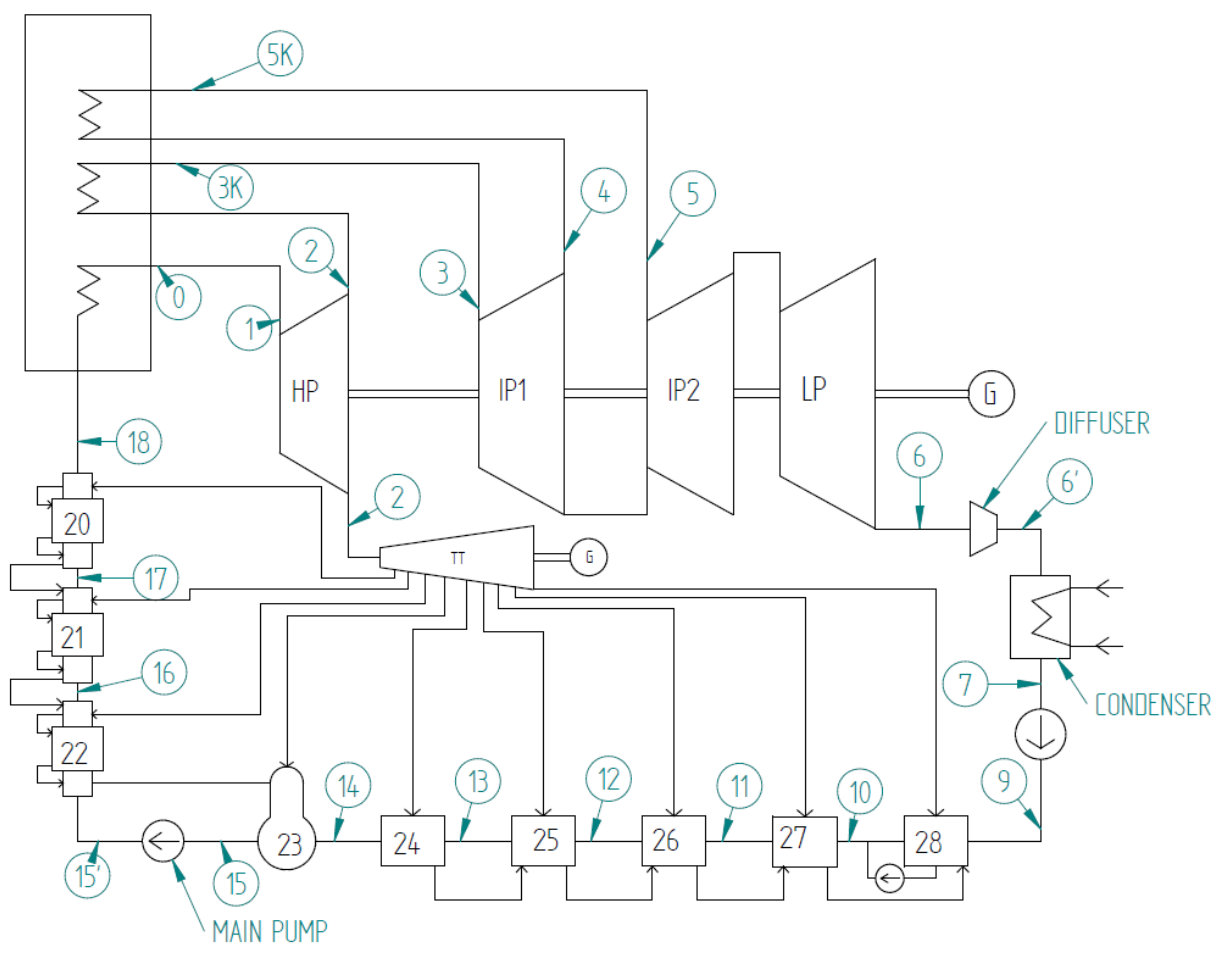

Fig. 1: Scheme of Enhanced Master Cycle

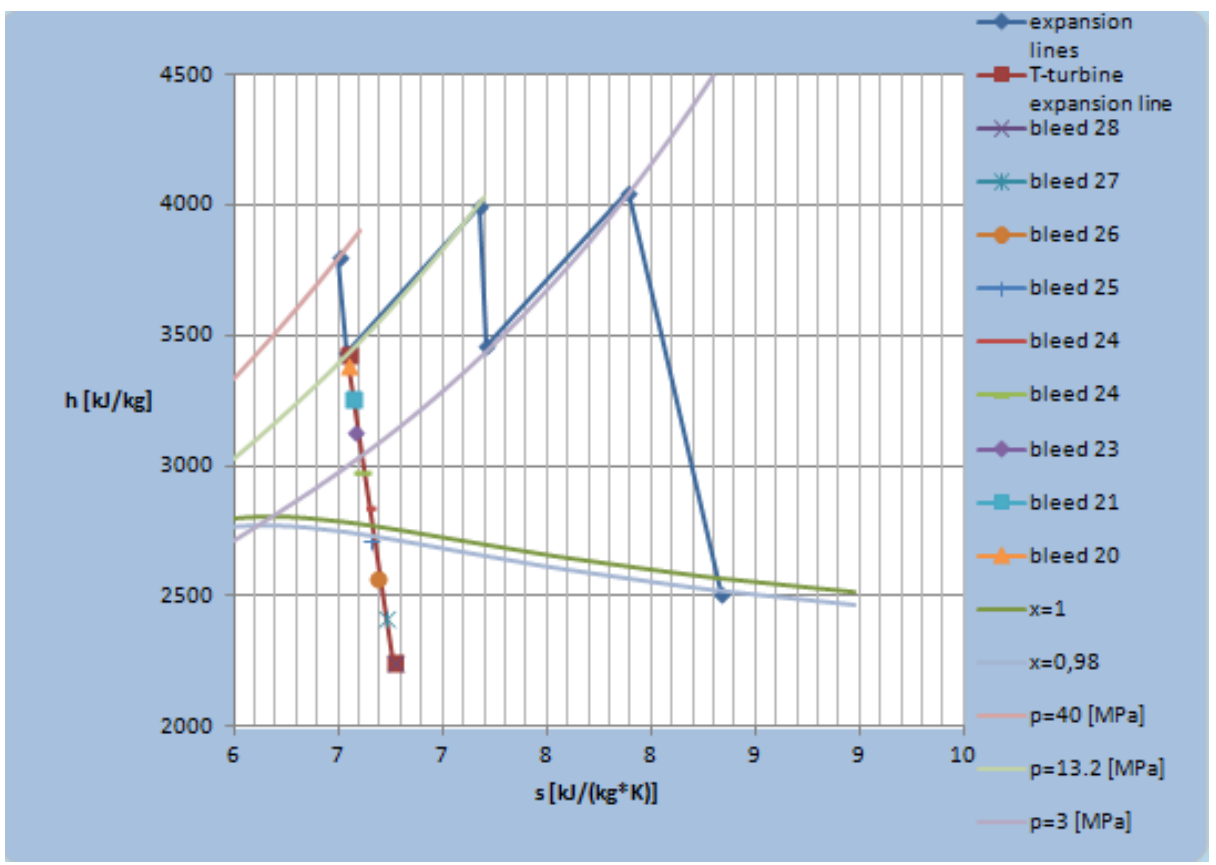

Fig. 2: Expansion lines in Enhanced Master Cycle 
In the above configuration, 9 bleedings with 9 regenerative heat exchangers including dearator are used, and steam is reheated twice. At the end of exhaust from low pressure turbine a diffuser is placed, which enables to regain a part of the kinetic energy from the steam and turns it into the static pressure. An auxiliary pump is placed after condenser. Expansion lines are presented on h-s (specific enthalpy-specific entropy) diagram on the Figure 2. All bleeds are marked on the TT expansion line.

\subsection{Results of calculations comparing three different configurations of discussed steam cycles}

Thermodynamic calculations have been conducted with steam tables IAPWS IF97 implemented in the X Steam program. Four configurations have been analyzed: classic double reheat cycle, classic Master Cycle, Enhanced Master Cycle and Enhanced Master Cycle, for which LP internal efficiency is increased by 1 percentage point. All internal efficiencies were the same for every cycle, apart from this one exception. Certain assumptions have been made: electric power is equal to $1000 \mathrm{MW}$, parameters of fresh steam are $740^{\circ} \mathrm{C}$ and $40 \mathrm{MPa}$, temperature of reheated steam is $760^{\circ} \mathrm{C}$ and backpressure is $3.8 \mathrm{kPa}$. Pressure after diffuser is $5 \%$ higher and is equal to 4 $\mathrm{kPa}$. Feed water temperature is $320^{\circ} \mathrm{C}$. Steam cycle could achieve slightly better efficiency with higher feed water temperature, but it would decrease boiler efficiency. Thermodynamic parameters of EMC are presented in the Table 1. Highest enthalpy can be observed after second reheat in point 5. Quality of steam at the end of expansion of low pressure turbine is high and water droplets should not be dangerous for turbine in this region. Steam quality at the end of a tuning turbine requires safety precautions.

Tab. 1: Thermodynamic parameters in points of the Enhanced Master Cycle(where p-absolute pressure [MPa], t-temperature $\left[{ }^{\circ} \mathrm{C}\right]$, specific enthalpy $[\mathrm{kJ} / \mathrm{kg}]$, specific entropy $\left[\mathrm{kJ} /\left(\mathrm{kg}{ }^{*} \mathrm{~K}\right)\right], \mathrm{x}$-vapour quality)

\begin{tabular}{|c|c|c|c|c|c|}
\hline & $\mathrm{p}[\mathrm{MPa}]$ & $\mathrm{t}\left[{ }^{\circ} \mathrm{C}\right]$ & $\mathrm{h}[\mathrm{kJ} / \mathrm{kg}]$ & $\mathrm{s}[\mathrm{kJ} /(\mathrm{kg} * \mathrm{~K})]$ & $\mathrm{x}[-]$ \\
\hline 0 & 40 & 740 & 3799.4 & 6.50 & steam overheated \\
\hline 1 & 39.60 & 739.2 & 3799.4 & 6.50 & steam overheated \\
\hline 2 & 13.90 & 540.6 & 3436.9 & 6.54 & steam overheated \\
\hline $2 \mathrm{~s}$ & 13.90 & 528.9 & 3405.4 & 6.50 & steam overheated \\
\hline 28 & 0.02 & 63.4 & 2247.5 & 6.76 & 0.844 \\
\hline $3 \mathrm{k}$ & 13.35 & 760.0 & 3999.4 & 7.17 & steam overheated \\
\hline 3 & 13.21 & 759.7 & 3999.4 & 7.17 & steam overheated \\
\hline 4 & 3.20 & 502.3 & 3460.1 & 7.21 & steam overheated \\
\hline $4 \mathrm{~s}$ & 3.20 & 489.8 & 3431.7 & 7.17 & steam overheated \\
\hline $5 \mathrm{k}$ & 3.07 & 760.0 & 4052.1 & 7.89 & steam overheated \\
\hline 5 & 3.04 & 759.9 & 4052.1 & 7.89 & steam overheated \\
\hline 6 & 0.0038 & 28.1 & 2505.9 & 8.34 & 0.981 \\
\hline $6 \mathrm{~s}$ & 0.0038 & 28.1 & 2371.5 & 7.89 & 0.926 \\
\hline 6 & 0.004 & 29.0 & 2512.9 & 8.34 & 0.983 \\
\hline 7 & 0.004 & 27.5 & 115.1 & 0.40 & water \\
\hline $9 \mathrm{~s}$ & 2.62 & 27.5 & 117.7 & 0.40 & water \\
\hline 9 & 2.62 & 27.6 & 118.0 & 0.40 & water \\
\hline 10 & 2.57 & 58.9 & 246.8 & 0.82 & water \\
\hline 11 & 2.52 & 90.4 & 378.8 & 1.20 & water \\
\hline 12 & 2.48 & 121.9 & 512.0 & 1.55 & water \\
\hline 13 & 2.43 & 153.4 & 647.0 & 1.87 & water \\
\hline 14 & 2.38 & 184.9 & 784.9 & 2.19 & water \\
\hline 15 & 2.34 & 216.4 & 927.0 & 2.48 & water \\
\hline $15 \mathrm{~s}$ & 46.40 & 224.2 & 978.4 & 2.48 & water \\
\hline 15 & 46.40 & 225.6 & 984.1 & 2.50 & water \\
\hline 16 & 45.60 & 257.0 & 1120.1 & 2.77 & water \\
\hline 17 & 44.80 & 288.5 & 1281.8 & 3.04 & water \\
\hline 18 & 44.00 & 320 & 1462.1 & 3.31 & water \\
\hline
\end{tabular}


Comparison of the calculated cycles is presented in the Table 2. The most efficient is Enhanced Master Cycle with increased LP internal efficiency, and the least efficient is Double Reheat Cycle. It should be noted that classic Master Cycle is more efficient than EMC without adjusted LP internal efficiency. Nevertheless, the reduction of steam mass flow through costly reheats is a significant advantage of the Enhanced Master Cycle. Double Reheat Cycle requires the higher amount of refractory materials in comparison with the Master Cycle. Enhanced Master Cycle could reduce amount of superalloys required for construction of boiler, heat exchangers, bleedings, pipelines and blades of first stages.

Tab. 2: Comparison of calculated cycles

\begin{tabular}{|c|c|c|c|c|c|}
\hline & $\begin{array}{c}\text { Net } \\
\text { efficiency } \\
{[-]}\end{array}$ & $\begin{array}{c}\text { Mass flow of } \\
\text { fresh steam } \\
{[\mathrm{kg} / \mathrm{s}]}\end{array}$ & $\begin{array}{c}\text { Mass flow of } \\
\text { first reheat } \\
{[\mathrm{kg} / \mathrm{s}]}\end{array}$ & $\begin{array}{c}\text { Mass flow of } \\
\text { second reheat } \\
{[\mathrm{kg} / \mathrm{s}]}\end{array}$ & $\begin{array}{c}\text { Total of mass flow on } \\
\text { superheaters [kg/s] }\end{array}$ \\
\hline double reheat cycle & $54.27 \%$ & 563.5 & 563.5 & 459.0 & 1585.9 \\
\hline Master Cycle & $54.53 \%$ & 593.9 & 385.9 & 385.9 & 1365.8 \\
\hline EMC & $54.34 \%$ & 621.9 & 334.7 & 334.7 & 1291.4 \\
\hline $\begin{array}{c}\text { EMC with adjusted } \\
\text { LP internal efficiency }\end{array}$ & $54.64 \%$ & 618.5 & 332.9 & 332.9 & 1284.4 \\
\hline
\end{tabular}

\section{Conclusions}

New Advanced Ultra-Supercritical steam power plants will be able to generate electricity with efficiency that highly exceeds 50\%. It has been shown that Enhanced Master Cycle could be the most efficient version of Rankine Cycle. Calculated net efficiency of EMC for considered parameters is 54.64\%. For the calculated case, Enhanced Master Cycle has net efficiency higher than Master Cycle for 0.11 percentage point. EMC can resolve problems with supercritical bleeds with high exergy and reduces amount of expensive refractory materials required for the construction of pipelines, boiler, bleedings, regenerative heat exchangers and blades of first stages.

\section{References}

Blaszczyk, A., Głuch, J.; Gardzilewicz A, (2011) Operating and economic conditions of cooling water control for marine steam turbine condensers, Polish maritime research .

Butrymowicz D, Głuch, J, Hajduk, T, (2009)Analysis of fouling thermal resistance of feed-water heaters in steam power plants , Polish maritime research.

Chenghao F., Dongsheng P., Xiang H., Wentai Z., Zengtao W. (2017)A Modified Master Cycle Off-Design Performance and Heat Rate Improvement Optimization, POWER-ICOPE2017-3063.

Cziesla F., Bewerunge J., Senzel A. (2009) Lünen - State-of-theArt Ultra Supercritical Steam Power Plant Under Construction, POWER-GEN Europe 2009, Kolonia, Germany.

Głuch S., Piwowarski M. (2018) Optimization of work parameters of advanced ultra supercritical power plant and modifications of steam cycle which increase efficiency, Instal.

Kjaer S., Drinhaus F. (2010) A Modified Double Reheat Cycle, Conference: ASME 2010 Power Conference.

Klotz H.,. Brandt C; (2008)Alstoms Target and Most Advanced Steam Turbine Generator Set E. ON $\square$ Power Plant Datteln 4.,Power Gen. Europe Conf., Milan.

Kowalczyk, T.; Gluch, J.; Ziolkowski, P. (2016) Analysis of possible application of high-temperature nuclear reactors to contemporary large-output steam power plants on ships, Polish maritime research .

Leizerovich A. (2008). Steam turbines for modern fossil-fuel power plans, the Fairmount Press Inc, New York.

Noppenau H. (2003) Concept and first operating experience with Avedøre 2, Research gate.

Piwowarski M. (2009) Optimization of steam cycles with respect to supercritical parameters, PMR.

Smarter. Cleaner. Steam Power.2018 STEAM POWER PRODUCT CATALOG - NEW BUILD UNITS.

Szewczuk-Krypa N., Drosińska-Komor M., Głuch J.,. Breńkacz Ł. (2018) Comparison analysis of selected nuclear power plants supplied with helium from high-temperature gas-cooled reactor, Polish maritime research.

Szewczuk-Krypa N.,. Milewska A, Głuch J. (2018) Comparative analysis of thermodynamic cycles of selected nuclear ship power plants with high-temperature helium-cooled nuclear reactor, Polish maritime research.

Tumanovskii A.G., Shvarts A.L., Somova E.V., Verbovetskii E.Kh., Avrutskii G. D., Ermakova S.V., Kalugin R.N., Lazarev M.V (2017) Review of the Coal-Fired, Over-Supercritical and Ultra-Supercritical Steam Power Plants, Pleiades Publishing, Thermal Engineering.

Witchman A., Depolt M. (2006) State of the art 800 steam power plant innovative supercritical and ultrasupercitical steam turbine generator sets. Power Generation, Siemens. 